\title{
CARACTERIZAÇÃO FÍSICA E QUÍMICA DE FRUTOS DE ABACATE VISANDO A SEU POTENCIAL PARA EXTRAÇÃO DE ÓLEO'
}

\author{
JOÃO SHOJIRO TANGO ${ }^{2}$, CÁSSIA REGINA LIMONTA CARVALHO ${ }^{3}$, NILBERTO BERNADO SOARES ${ }^{3}$
}

\begin{abstract}
RESUMO - Vinte e quatro variedades de abacate provenientes da coleção de abacateiros, situada no Núcleo Experimental de Campinas e pertencente ao Centro de Fruticultura do Instituto Agronômico de Campinas (IAC), foram analisadas quanto às proporções dos componentes dos frutos (polpa, casca e caroço) e quanto aos teores de lipídeos e umidade da polpa fresca. Determinaram-se, na maioria das variedades, o perfil de ácidos graxos dos óleos extraídos da polpa e, em algumas das variedades, a composição química dos caroços dos frutos. As variedades mais indicadas para serem cultivadas, visando à utilização industrial dos frutos para a extração de óleo, baseando-se nos teores de lipídeos encontrados na polpa fresca e estabelecidos acima de 18\%, foram: Anaheim, Carlsbad, Collinson, Fuerte, Glória, Hass, Itzamna, Mayapan, Ouro Verde e Wagner. O período de colheita dessas variedades estendeu-se por sete meses, iniciando em maio e terminando em novembro. Houve correlações lineares negativas, altamente significativas, entre as proporções de polpa com caroço e casca dos frutos, entre os teores de umidade e lipídeos nas polpas e entre os teores de umidade e amido nos caroços dos frutos. Ocorreram grandes variações na composição de ácidos graxos constituintes do óleo das polpas e na composição química das sementes.
\end{abstract}

Termos para indexação: Persea americana; época de colheita; componentes dos frutos; teor de óleo; ácidos graxos; composição química das sementes.

\section{PHYSICAL AND CHEMICAL CHARACTERIZATION OF AVOCADO FRUITS AIMING ITS POTENCIAL FOR OIL EXTRACTION}

\begin{abstract}
Twenty-four avocado varieties from the germplasm collection of the Fruit Center of the Agronomic Institute of Campinas, were evaluated as a possible raw material for oil extraction. The varieties were analyzed concerning the proportions of fruit components (pulp, peel and seed) and the amounts of moisture and fatty substances found in the fresh pulp. The fatty acid profile of the oils extracted from the pulp was determined in most of the varieties, and in some varieties also the fruit seeds chemical composition. The Anaheim, Carlsbad, Collinson, Fuerte, Glória, Hass, Itzamna, Mayapan, Ouro Verde and Wagner fruit varieties presented an oil content in the pulp higher than 18\% on a fresh weight basis, which were considered the most suitable for oil extraction. The harvest of these varieties started in May and finished in November. There were highly significant negative linear correlations between the proportions of the fruits pulp and the seeds, the pulp and the peel, between the pulps fatty substances and moisture contents and between the seeds moisture and starch content. The composition of the pulp oil fatty acids and the seeds chemical composition presented great variation among the varieties.
\end{abstract}

Index terms: Persea americana; harvest season; fruit components; oil content; fatty acids; seeds chemical composition.

\section{INTRODUÇÃO}

O abacateiro é cultivado em quase todos os Estados do Brasil. Trata-se de uma planta frutífera das mais produtivas por unidade de área cultivada (Tango e Turatti, 1992). Um grande número de variedades de abacate é encontrado nas diversas regiões do território nacional, cujos frutos apresentam composição química muito variável. Estudo anteriormente realizado com algumas variedades cultivadas no Estado de São Paulo mostrou grande variação quanto aos teores de lipídeos na polpa dos frutos (Tango et al., 1972). Frutos que apresentam altos teores de lipídeos na polpa poderão constituir-se em uma matéria-prima importante para obtenção de óleo, considerando-se a quantidade de óleo que pode ser obtida por unidade de área cultivada, a qual, de acordo com estudos comparativos realizados por Canto et al. (1980) com algodão, amendoim e soja, é bem mais elevada do que de qualquer dessas sementes oleaginosas cultivadas. Além do que, trata-se o abacateiro de uma planta perene, podendo ser cultivada em áreas de topografia acidentada, e o óleo de seus frutos apresenta interessantes características químicas (Tango e Turatti, 1992).

O óleo de abacate assemelha-se muito com o óleo de oliva (importado e altamente consumido no País), por ser extraído da polpa dos frutos e pela similaridade de suas propriedades físico-químicas, principalmente pela composição de seus ácidos graxos, predominando em ambos o ácido oléico (Canto et al., 1980; Bleinroth e Castro, 1992; Soares et al., 1992; Tango e Turatti, 1992). Esses óleos são ricos em ácidos graxos ômega nove que parecem apresentar efeitos benéficos para a saúde do consumidor, em relação à prevenção de doenças cardiovasculares (Ahmed e Barmore, 1990; Rebollo et al., 1998).

Estudos mostram que o consumo de dietas ricas em gorduras monoinsaturadas (ácido oléico), em substituição de gorduras saturadas, exerce seletivos efeitos fisiológicos sobre humanos, reduzindo os níveis de colesterol total, de triglicerídeos e de LDL-colesterol ${ }^{4}$, sem alterar a fração HDL-colesterol ${ }^{5}$ do plasma (Rebollo et al., 1998; Turatti et al., 2002). Outra informação importante, observada com o consumo de dietas ricas em ácido oléico, foi a redução dos níveis de fibrinogênio ${ }^{6}$ do plasma, visto que essa fração reconhecidamente atua no desenvolvimento de lesões das artérias, servindo como prognóstico de doenças coronárias (Rebollo et al., 1998).

O pequeno volume de óleo de abacate produzido atualmente por alguns países é utilizado na sua forma bruta, pelas indústrias farmacêuticas e de cosméticos, notadamente pelas suas características físicas e químicas, uma vez que faz parte de sua composição, em elevadas quantidades, a fração insaponificável responsável por propriedades regenerativas da epiderme. Além dessa propriedade, o óleo de abacate apresenta: fácil absorção pela pele, sendo usado como veículo de substâncias medicinais; poder de absorção de perfumes, de grande valia para a indústria de cosméticos; fácil formação de emulsão, tornando-o ideal para fabricação de sabões finos e, se refinado, pode ser usado para fins alimentícios (Canto et al., 1980; Tango e Turatti, 1992).

Soares et al. (1992) mencionam que, além da possibilidade de

${ }^{1}$ (Trabalho 064/2003). Recebido: 04/04/2003. Aceito para publicação: 06/02/2004.

${ }^{2}$ Pesquisador Científico, Instituto de Tecnologia de Alimentos - ITAL/APTA/SAA, Caixa Postal 139, 13012-970, Campinas-SP.

${ }^{3}$ Pesquisadores Científicos, Instituto Agronômico de Campinas - IAC/APTA/SAA - Caixa Postal 28, 13012-970 Campinas-SP. Endereços eletrônicos: climonta@iac.sp.gov.br; nilberto@iac.sp.gov.br.

${ }^{4}$ LDL - lipoproteínas de baixa densidade, nos humanos são as principais transportadoras do colesterol do plasma para os tecidos (Turatti et al., 2002).

${ }^{5} \mathrm{HDL}$ - lipoproteínas de alta densidade, responsáveis pelo transporte do colesterol dos tecidos para o fígado, com função protetora contra a aterogênese e seus efeitos patogênicos (Turatti et al., 2002).

${ }^{6}$ Fibrinogênio - proteína plasmática de alta densidade, que se converte em fibrina (parte essencial do coágulo sanguíneo) (Rebollo et al., 1998). 
TABELA 1 - Variedades de abacate e respectivas épocas de maturação dos frutos da coleção de germoplasma do Centro de Fruticultura - Núcleo Experimental de Campinas - IAC, Campinas, SP, 1990 (Altitude = 674 m; Latitude = 220 54' S; Longitude =47O 05' W).

\begin{tabular}{cc||cc}
\hline VARIEDADES & ÉPOCA DE COLHEITA & VARIEDADES & ÉPOCA DE COLHEITA \\
\hline Pollock & Janeiro - Março & Fuerte & Julho - Agosto \\
Barker & Fevereiro - Março & Glória & Julho - Agosto \\
Simmonds & Fevereiro - Março & Hass & Julho - Setembro \\
Waldin & Março - Abril & Mac Donald & Julho - Setembro \\
Vitória & Abril - Maio & Winslow & Agosto - Setembro \\
Quintal & Maio - Junho & Itzamna & Agosto - Outubro \\
Westin & Maio - Junho & Carlsbad & Setembro - Outubro \\
Collinson & Maio - Julho & Mayapan & Setembro - Outubro \\
Fortuna & Maio - Julho & Monte d'Este & Setembro - Outubro \\
Winslowson & Junho - Julho & Sinaloa & Setembro - Outubro \\
Linda & Junho - Agosto & Wagner & Setembro - Outubro \\
Anaheim & Julho - Agosto & Ouro Verde & Setembro - Novembro \\
\hline
\end{tabular}

introduzir o óleo de abacate puro para uso comestível como substituto do óleo de oliva, uma das alternativas para oferecer ao consumidor brasileiro um produto de superior qualidade seria a produção de óleo de oliva e de abacate mesclado, em substituição às misturas de óleo de oliva com óleos vegetais (principalmente óleo de soja), normalmente oferecidas pelo mercado interno com a finalidade de diminuir os custos de importação do azeite de oliva no Brasil.

Diversos processos extrativos do óleo da polpa têm sido estudados, tais como: extração por centrifugação da polpa úmida; extração do óleo por solventes utilizando polpa liofilizada, polpa seca a $70^{\circ} \mathrm{C}$ ou com prévia fermentação anaeróbica; extração por prensagem hidráulica contínua ou descontínua, com adição de material auxiliar de prensagem; por tratamento da polpa fresca com produtos químicos ou por processos enzimáticos ou, mesmo, por processos convencionais de extração de óleo para sementes oleaginosas. Os rendimentos desses processos variam de 56 a 95\% de óleo extraído (Jimenez, 1954; Montano et al., 1962; Jaubert, 1970; Sadir, 1972a; Canto et al., 1980; Turatti et al., 1985; Tango e Turatti, 1992; Bizimana et al., 1993).

Alguns trabalhos sobre refinação de óleo bruto de abacate foram realizados em escala de laboratório, mostrando principalmente as características físicas e químicas dos óleos refinados (Montano et al., 1962; Jaubert, 1970; Smith e Winter, 1970/71; Sadir, 1972b; Tango et al., 1972; Santos, 1985; Soares et al., 1991; Tango e Turatti, 1992). Soares et al. (1992) avaliaram sensorialmente misturas de óleo de abacate refinado em laboratório com azeite de oliva comercial, determinando, por meio de um painel de julgadores, os limites de detecção da cor, aroma e sabor das misturas empregadas.

Diante das alternativas de utilização do óleo de abacate, principalmente para fins alimentares, esse trabalho teve como objetivo estudar variedades existentes na coleção de abacateiro do Instituto Agronômico de Campinas, visando a identificar as mais adequadas para estabelecimento de plantações para obtenção de óleo, bem como caracterizar, em algumas das variedades avaliadas, o subproduto caroço, tendo em vista o seu aproveitamento.

\section{MATERIAL E MÉTODOS}

1. Matéria-prima. Frutos de abacate de diferentes variedades foram colhidos quando estavam completamente desenvolvidos de plantas da coleção de germoplasma do Centro de Fruticultura do IAC, Campinas-SP. As épocas de maturação dos frutos de abacate, assim como as diferentes variedades estudadas, são apresentadas na Tabela 1.

2. Determinação das percentagens das porções polpa, casca e caroço. Frutos de cada variedade foram conservados à temperatura ambiente no laboratório até o amadurecimento (apresentando consistência macia) e, em seguida, foram determinadas as percentagens de polpa, casca e caroço em relação à massa total dos frutos.

3. Determinação de umidade e lipídeos na polpa dos frutos.
Teores de umidade foram determinados desidratando-se as polpas dos frutos em estufa a vácuo a $70^{\circ} \mathrm{C}$ até a obtenção de massa constante, segundo o método Ca 2d-25 da AOCS (Walker, 1979). Os lipídeos foram extraídos e quantificados nas polpas desidratadas, utilizando-se do aparelho de Butt e hexano como solvente de extração, seguindo os procedimentos do método Ba3-38 da AOCS (Walker, 1979).

4. Composição em ácidos graxos dos óleos. Ésteres metílicos preparados pelo método Ce 2-66 da AOCS (Walker, 1979), a partir da saponificação dos óleos extraídos das polpas dos frutos, foram utilizados para definir o perfil de ácidos graxos das variedades de abacate. A separação, identificação e quantificação dos ácidos graxos foram determinadas por meio de cromatografia em fase gasosa, baseando-se no método Ce 1-62 da AOCS (Walker, 1979). Empregou-se um cromatógrafo Philips, modelo PU-4550, equipado com detector de ionização de chama e coluna capilar CP-SIL 88 contendo $0,20 \mu \mathrm{m}$ de polietilenoglicol, de 50 metros de comprimento e $0,25 \mathrm{~mm}$ de diâmetro interno. Utilizou-se hidrogênio como gás de arraste $(3 \mathrm{~mL} / \mathrm{min})$ e, para o sistema de detecção, em conjunto com ar sintético, nas respectivas vazões de 20 e $240 \mathrm{~mL} / \mathrm{min}$. As temperaturas usadas foram fixadas a $180^{\circ} \mathrm{C}$ para coluna, $270^{\circ} \mathrm{C}$ para o injetor e $300^{\circ} \mathrm{C}$ para o detector, registrando-se um período de corrida cromatográfica de 40 minutos. A quantificação dos ácidos graxos foi realizada aplicando-se o método de normalização, que consiste em comparar, em termos de porcentagem, a área integrada de cada substância obtida no cromatograma pela área total de todas as substâncias analisadas.

5. Composição química dos caroços. As determinações analíticas efetuadas nos caroços extraídos dos abacates e os respectivos métodos aplicados foram os seguintes: umidade, por aquecimento direto utilizando o método Ca 2d-25 exposto pela AOCS (Walker, 1979); lipídeos, determinados pelo método Ba3-38 da AOCS (Walker, 1979); proteína bruta e resíduo mineral fixo foram determinados pelos métodos descritos pela AOAC (Williams, 1984); fibra, analisada de acordo com o método de Scharrer e Kürschner (Beythien e Diemair, 1963); amido, segundo metodologia de Ewers, modificada por Hadorn e Doewelaar (Schormuller, 1967) e substâncias fenólicas, de acordo com a descrição de Price e Butler (Ichimaru et al., 1982).

\section{RESULTADOS E DISCUSSÃO}

A Tabela 1 mostra que a época de colheita dos frutos das diversas variedades de abacate, no município de Campinas, inicia em janeiro e termina em novembro. As épocas de colheita dos frutos dessas variedades podem ser antecipadas ou atrasadas, em relação às épocas que foram observadas neste estudo, de acordo com a latitude e altitude do local de cultivo (Sentelha et al., 1995).

Os dados sobre as percentagens das porções polpa, caroço e casca, nos frutos das diversas variedades, encontram-se na Tabela 2.

O conteúdo de polpa apresentou um coeficiente de variação (CV) de 9,2\%, variando entre 52,9 e $81,3 \%$ em relação à massa do fruto. 
TABELA 2 - Proporções dos componentes polpa, caroço e casca nos frutos de abacate. Campinas-SP, 1990.

\begin{tabular}{lcccc}
\hline VA RIEDADES & $\begin{array}{c}\text { POLPA } \\
(\mathbf{\%})\end{array}$ & $\begin{array}{c}\text { CAROÇO } \\
\mathbf{( \% )}\end{array}$ & $\begin{array}{c}\text { CASCA } \\
\mathbf{( \% )}\end{array}$ & $\begin{array}{c}\text { CAROÇO } \\
\text { + CASCA } \\
\mathbf{( \% )}\end{array}$ \\
\hline Anaheim & 63,9 & 20,4 & 15,7 & 36,1 \\
\hline Barker & 67,3 & 19,3 & 13,4 & 32,7 \\
\hline Carlsbad & 74,4 & 16,1 & 9,5 & 25,6 \\
\hline Collinson & 73,0 & 16,8 & 10,2 & 27,0 \\
\hline Fortuna & 75,7 & 12,5 & 11,8 & 24,3 \\
\hline Fuerte & 65,8 & 22,3 & 11,9 & 34,2 \\
\hline Glória & 72,0 & 13,3 & 14,7 & 28,0 \\
\hline Hass & 67,5 & 19,0 & 13,5 & 32,5 \\
\hline Itzamna & 58,3 & 19,7 & 22,0 & 41,7 \\
\hline Linda & 69,6 & 15,7 & 14,7 & 30,4 \\
\hline Mac Donald & 52,9 & 24,2 & 22,9 & 47,1 \\
\hline Mayapan & 60,8 & 17,2 & 22,0 & 39,2 \\
\hline Monte d'Este & 64,1 & 13,1 & 22,8 & 35,9 \\
\hline Ouro Verde & 73,7 & 12,7 & 13,6 & 26,3 \\
\hline Pollock & 73,1 & 12,8 & 14,1 & 26,9 \\
\hline Quintal & 81,3 & 10,1 & 8,6 & 18,7 \\
\hline Simmonds & 71,8 & 14,7 & 13,5 & 28,2 \\
\hline Sinaloa & 73,7 & 16,0 & 10,3 & 26,3 \\
\hline Vitória & 68,0 & 19,8 & 12,2 & 32,0 \\
\hline Wagner & 65,2 & 24,5 & 10,3 & 34,8 \\
\hline Waldin & 61,4 & 25,1 & 13,5 & 38,6 \\
\hline Westin & 73,8 & 14,8 & 11,4 & 26,2 \\
\hline Winslow & 68,9 & 19,0 & 12,1 & 31,1 \\
\hline Winslowson & 70,0 & 18,8 & 11,2 & 30,0 \\
\hline MÉDIA & $\mathbf{6 8 , 6}$ & $\mathbf{1 7 , 4}$ & $\mathbf{1 4 , 0}$ & $\mathbf{3 1 , 4}$ \\
\hline CV (\%) & $\mathbf{9 , 2}$ & $\mathbf{2 3 , 6}$ & $\mathbf{3 0 , 2}$ & $\mathbf{2 0 , 1}$ \\
\hline Nest caso, & 04 & \\
\hline
\end{tabular}

${ }^{1}$ Neste caso, menor ou maior coeficiente de variação indica menor ou maior variabilidade do componente analisado em relação ao germoplasma.

Essa porção é a de maior interesse, pois nela concentra-se a maior parte dos lipídeos contidos no fruto, uma vez que, no caroço e na casca, os teores dessas substâncias são reduzidos (Tango e Turatti, 1992).

Apesar de as variedades de abacate possuírem caracteres distintos, como diferentes tamanhos e massas dos frutos e sementes, pela avaliação dos coeficientes de variação respectivos às proporções de polpa, caroço e casca, observou-se que houve menor dispersão dos valores de polpa; os coeficientes de variação encontrados para os conteúdos de caroço e casca das variedades de abacate foram de duas a três vezes maiores do que a variação dos resultados para a polpa. No entanto, correspondências funcionais lineares entre as proporções de polpa e as de caroço e casca dos frutos $(\mathrm{r}=-0,800$ e $\mathrm{r}=-0,764$, respectivamente; Tabela 3 ), foram encontradas para as vinte e quatro variedades de abacate, resultados esses já esperados. Ainda que tenham sido observados coeficientes de regressões lineares baixos para as equações das retas "polpa x caroço" e "polpa x casca" $\left(\mathrm{R}^{2}=0,567\right.$ e $\mathrm{R}^{2}=$ 0,583 , respectivamente; Tabela 3 ), as correspondências foram altamente significativas. Observou-se que os frutos com maiores percentagens de polpa apresentaram menores proporções de caroço e casca, e os com menores proporções de polpa tiveram maiores percentagens de caroço e casca.

Os caroços e cascas que corresponderam acerca de um terço das massas dos frutos (31,4\% em média; Tabela 2$)$, devem ser separados na fase de preparo para o processamento de extração de óleo, para não reduzir a capacidade de extração dos equipamentos. Seria de grande interesse para o processo de extração de óleo obter variedades de abacate com menores percentagens de caroço e casca, tendo em vista o maior rendimento da polpa. A variedade Quintal destacou-se para esta característica, apresentando as menores proporções de casca e semente $(18,7 \%)$ e, conseqüentemente, a maior porcentagem de polpa fresca $(81,3 \%)$. O inverso ocorreu para a variedade Mac Donald, com aproximadamente $50 \%$ de casca e caroço, seguindo Itzamna, Mayapan, Waldin, Anaheim, Monte d'Este, Wagner e Fuerte; as demais variedades apresentaram valores próximos ou abaixo da média geral (31,4\% de casca e semente).

$\mathrm{Na}$ Tabela 4, encontram-se os conteúdos de umidade e de lipídeos das polpas dos frutos de abacate das diversas variedades analisadas. Os teores de umidade nas polpas variaram entre 57,2 e 87,9\% $(\mathrm{CV}=10,6 \%)$ e os de lipídeos entre 5,3 e 31,1\%, com um coeficiente de variação dos resultados muito alto $(44,1 \%)$, indicando que o germoplasma de abacate avaliado mostrou maior variabilidade quanto ao conteúdo de lipídeos. Os teores de umidade e de lipídeos apresentaram alta correlação linear negativa nas polpas dos frutos $(r=-0,993$, Tabela 3; Figura 1). As polpas frescas dos frutos, que apresentaram teores baixos de lipídeos, tiveram percentagens de umidade mais elevadas, ocorrendo o inverso para as polpas com teores de lipídeos mais elevados. A alta correlação entre umidade e lipídeos deve-se ao fato de que a soma dos teores dessas substâncias corresponde à grande parte da massa das polpas; como pode ser visto na Tabela 4, a soma dos teores corresponde, em média, a aproximadamente $92 \%$ da polpa. Considerando-se as polpas de frutos com mais de $18,0 \%$ de lipídeos (valores acima da média geral, $16,0 \%$ ), a média de teores de umidade foi de $68,1 \%$, enquanto, nas que possuem menos do que $18,0 \%$ de lipídeos, a média foi de $81,1 \%$.

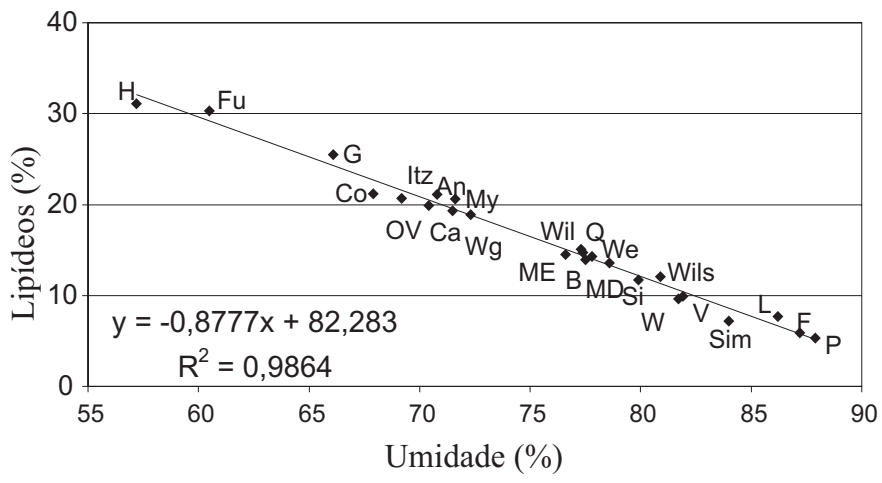

FIGURA 1 - Regressão linear dos teores de umidade e de lipídeos na polpa de abacate. As variedades como os valores plotados correspondem à Tabela 4.

TABELA 3 - Regressões lineares e coeficientes de correlação referentes às relações entre alguns dos componentes encontrados nos frutos, polpas e caroços dos abacates.

\begin{tabular}{|c|c|c|c|c|c|}
\hline & $\begin{array}{l}\text { Equação linear } \\
(y=a+b x)\end{array}$ & $\mathrm{R}^{2 \mathrm{a}}$ & $\begin{array}{c}\mathrm{r}^{\mathbf{b}} \\
\text { (calculado) }\end{array}$ & $\begin{array}{c}\mathrm{r}^{\mathbf{c}} \\
\text { (tabelado) }\end{array}$ & Prova de significância \\
\hline Polpa X Caroço (frutos) & $y=-0,4896 x+51,003$ & 0,567 & $-0,800$ & 0,515 & $\begin{array}{c}\text { RAC }^{\mathbf{d}} \\
\mathrm{r} \text { (calculado })>\mathrm{r} \text { (tabelado })\end{array}$ \\
\hline Polpa X Casca (frutos) & $y=-0,5117 x+49,104$ & 0,583 & $-0,764$ & 0,515 & RAC \\
\hline Umidade X Lipídeos (polpas) & $y=-0,88 x+82,283$ & 0,986 & $-0,993$ & 0,515 & RAC \\
\hline Umidade X Amido (caroços) & $y=-1,02 x+83,289$ & 0,912 & $-0,955$ & 0,641 & RAC \\
\hline
\end{tabular}

${ }^{a}$ Coeficiente de regressão linear das equações.

${ }^{\text {b }}$ Coeficiente de correlação calculado a 99\%; valores negativos por haver correlação linear negativa.

c Valores críticos de r (tabelados), transcritos de FISHER (1944), para nível de 1\% com N-2 graus de liberdade.

d RAC - Resultados altamente correlacionados. 
TABELA 4 - Teores de umidade e de lipídeos da polpa fresca das variedades de abacate, Campinas-SP, 1990.

\begin{tabular}{lcc}
\hline VARIEDADES & $\begin{array}{c}\text { UMIDADE } \\
(\mathbf{\%})\end{array}$ & $\begin{array}{c}\text { LIPÍDEOS } \\
\mathbf{( \% )}\end{array}$ \\
\hline Hass (H) & 57,2 & $31,1 \mathrm{a}^{\mathbf{2}}$ \\
\hline Fuerte (Fu) & 60,5 & $30,3 \mathrm{~b}$ \\
\hline Glória (G) & 66,1 & $25,5 \mathrm{c}$ \\
\hline Collinson (Co) & 67,9 & $21,2 \mathrm{~d}$ \\
\hline Anaheim (An) & 70,8 & $21,1 \mathrm{de}$ \\
\hline Itzamna (Itz) & 69,2 & $20,7 \mathrm{def}$ \\
\hline Wagner (Wg) & 71,6 & $20,6 \mathrm{defg}$ \\
\hline Ouro Verde (OV) & 70,4 & $19,9 \mathrm{gh}$ \\
\hline Carlsbad (Ca) & 71,5 & $19,3 \mathrm{hi}$ \\
\hline Mayapan (My) & 72,3 & $18,9 \mathrm{i}$ \\
\hline Winslow (Wil) & 77,3 & $15,1 \mathrm{j}$ \\
\hline Quintal (Q) & 77,4 & $14,7 \mathrm{jk}$ \\
\hline Monte d'Este (ME) & 76,6 & $14,5 \mathrm{jkl}$ \\
\hline Mac Donald (MD) & 77,8 & $14,3 \mathrm{klm}$ \\
\hline Barker (B) & 77,5 & $13,9 \mathrm{lmn}$ \\
\hline Westin (We) & 78,6 & $13,6 \mathrm{mn}$ \\
\hline Winslowson (Wils) & 80,9 & $12,1 \mathrm{o}$ \\
\hline Sinaloa (Si) & 79,9 & $11,7 \mathrm{o}$ \\
\hline Vitória (V) & 81,9 & $9,9 \mathrm{p}$ \\
\hline Waldin (Wa) & 81,7 & $9,6 \mathrm{p}$ \\
\hline Linda (L) & 86,2 & $7,7 \mathrm{q}$ \\
\hline Simmonds (Sim) & 84,0 & $7,2 \mathrm{q}$ \\
\hline Fortuna (Fo) & 87,2 & $5,9 \mathrm{r}$ \\
\hline Pollock (P) & 87,9 & $5,3 \mathrm{r}$ \\
\hline MÉDIA & $\mathbf{7 5 , 5}$ & $\mathbf{4 4 , 1}$ \\
\hline CV (\%) & $\mathbf{1 0 , 6}$ & \\
\hline${ }^{3}$ Médias de três determinações analíticas. & \\
${ }^{2}$ Médias seguidas pela mesma letra não diferem significamente entre si peloTeste \\
de Tukey, a 5\%. & & \\
${ }^{3}$ Menor ou maior coeficiente de variação indica menor ou maior variabilidade do \\
componente analisado em relação ao germoplasma.
\end{tabular}

A alta correlação linear negativa de 0,993 (Tabela 3; Figura1) encontrada no presente estudo, entre os conteúdos de óleo e umidade das polpas dos frutos, foi igualmente observada por outros autores. Ahmed e Barmore (1990) citam que Swarts, em artigo publicado em 1976, demonstrou existir uma correlação negativa entre o conteúdo de umidade e óleo de frutos analisados, em que tal correlação derivou em procedimento prático para a dosagem de óleo em abacates. Esses autores comentam ainda que Swarts, em 1978, usou, na África do Sul, o conteúdo de umidade como forma de medir a maturidade dos frutos de abacate. No Chile, Olaeta e Undurraga (1995), ao avaliarem os teores de umidade e de óleo de oito cultivares de abacate, encontraram correlações negativas entre 0,92 e 0,98 e, a partir de modelos de regressão simples, estimaram a percentagem de óleo e o índice de maturação de abacates.

O elevado conteúdo de umidade na polpa fresca constitui no principal óbice para obtenção de óleo de abacate, afetando o rendimento de extração e o custo de produção. Dessa forma, as variedades mais indicadas para serem cultivadas para a produção de frutos para a extração de óleo, levando-se em conta os teores de lipídeos nas polpas acima de $18 \%$ (valores estatisticamente diferenciados da média geral) e com menores percentagens de umidade, seriam Hass, Fuerte e Glória, vindo a seguir as variedades Collinson, Anaheim, Itzamna, Wagner, Ouro Verde, Carlsbad e Mayapan. A produção dessas cultivares, com teores mais elevados de lipídeos, ocorreu no município de Campinas, em grande parte do ano, iniciando em maio e terminando em novembro (Tabela 1). A alta produção de óleo e diferentes épocas de maturação das variedades de abacate são algumas das características e fatores essenciais para a viabilidade de implantação de plantações de abacateiro objetivando a extração de óleo. Por ser a matéria-prima perecível, é de interesse tê-la em grande parte do ano a fim de evitar custos de armazenamento.

Vale ressaltar que as percentagens de umidade nos frutos de abacate diminuem com a maturação e, normalmente, são influenciadas pelas condições climáticas, sendo menores na época de inverno, cujo período tem menor intensidade de chuvas (Bleinroth e Castro, 1992). Das variedades com teores de lipídeos acima da média, algumas foram

TABELA 5 - Composição em ácidos graxos do óleo da polpa de frutos das variedades de abacate analisadas, Campinas-SP, 1990.

\begin{tabular}{|c|c|c|c|c|c|}
\hline \multirow{3}{*}{ VARIEDADES } & \multicolumn{5}{|c|}{ ÁCIDOS GRAXOS (\%) } \\
\hline & \multirow{2}{*}{$\begin{array}{c}\text { Palmítico }^{1} \\
(16: 0)\end{array}$} & \multirow{2}{*}{$\begin{array}{c}\text { Palmitoléico }^{1} \\
\left(\begin{array}{ll}16: 1 & 9\end{array}\right)\end{array}$} & \multirow{2}{*}{$\begin{array}{c}\text { Esteárico }^{1} \\
(18: 0)\end{array}$} & \multirow{2}{*}{$\begin{array}{l}\text { Oléico }^{1} \\
\left(\begin{array}{ll}18: 1 & 9\end{array}\right)\end{array}$} & Linoléico $^{1}$ \\
\hline & & & & & $(18: 2 \quad 9,12)$ \\
\hline Anaheim & 23,3 & 7,6 & 0,4 & 53,0 & 15,4 \\
\hline Collinson & 20,6 & 2,9 & 0,7 & 63,1 & 11,8 \\
\hline Fuerte & 20,2 & 7,9 & 0,4 & 61,4 & 10,1 \\
\hline Glória & 22,6 & 8,1 & 0,5 & 56,1 & 12,3 \\
\hline Hass & 24,5 & 13,3 & 0,3 & 47,7 & 14,2 \\
\hline Itzamna & 24,2 & 5,8 & 0,4 & 47,3 & 21,2 \\
\hline Linda & 18,9 & 7,1 & 0,4 & 58,8 & 12,9 \\
\hline Mac Donald & 35,2 & 9,4 & $\operatorname{tr}^{2}$ & 40,8 & 14,4 \\
\hline Mayapan & 29,8 & 16,8 & 0,4 & 37,9 & 13,7 \\
\hline Monte d'Este & 14,5 & 5,0 & 0,5 & 51,9 & 16,9 \\
\hline Ouro Verde & 18,3 & 6,8 & 0,5 & 60,6 & 13,2 \\
\hline Pollock & 22,0 & 8,6 & 0,4 & 57,7 & 13,1 \\
\hline Quintal & 19,0 & 7,6 & 0,5 & 65,2 & 9,3 \\
\hline Simmonds & 26,3 & 10,3 & 0,5 & 47,1 & 14,0 \\
\hline Sinaloa & 25,7 & 7,9 & 0,5 & 52,1 & 12,9 \\
\hline Vitória & 30,1 & 5,2 & 0,6 & 48,7 & 14,1 \\
\hline Wagner & 23,2 & 7,8 & $\operatorname{tr}$ & 58,9 & 10,1 \\
\hline Waldin & 29,0 & 8,2 & 0,4 & 47,0 & 14,3 \\
\hline Westin & 23,0 & 7,9 & 0,4 & 56,4 & 11,9 \\
\hline Winslow & 27,7 & 4,2 & 0,5 & 57,1 & 10,5 \\
\hline Winslowson & 30,9 & 4,9 & 0,6 & 52,0 & 11,4 \\
\hline MÉDIA & 24,2 & 7,8 & 0,4 & 53,4 & 13,2 \\
\hline $\mathrm{CV}(\%)^{3}$ & 20,6 & 39,1 & 21,4 & 13,5 & 19,8 \\
\hline
\end{tabular}

${ }^{1}$ Médias de três determinações analíticas.

${ }^{2} \operatorname{tr}$ - ácido graxo presente em quantidades traço.

${ }^{3}$ Menor ou maior coeficiente de variação indica menor ou maior variabilidade do componente analisado em relação ao germoplasma. 
TABELA 6 - Perfil de ácidos graxos de óleos de abacate e de várias fontes vegetais, segundo diversos autores.

\begin{tabular}{|c|c|c|c|c|c|}
\hline & \multicolumn{5}{|c|}{ ÁCIDOS GRAXOS (\%) } \\
\hline & $\begin{array}{l}\text { Palmítico } \\
(16: 0)\end{array}$ & $\begin{array}{c}\text { Palmitoléico } \\
(16: 1 \omega 9)\end{array}$ & $\begin{array}{l}\text { Esteárico } \\
(18: 0)\end{array}$ & $\begin{array}{c}\text { Oléico } \\
(18: 1 \omega 9)\end{array}$ & $\begin{array}{c}\text { Linoléico } \\
(18: 2 \omega 9,12)\end{array}$ \\
\hline $\begin{array}{l}\text { Óleo de abacate de diferentes variedades, extraído com } \\
\text { solvente }{ }^{1}\end{array}$ & $14,5-35,2$ & $2,9-16,8$ & $\operatorname{tr}-0,7$ & $37,9-65,2$ & $9,4-21,2$ \\
\hline $\begin{array}{l}\text { Óleo de abacate de diferentes variedade, extraído com } \\
\text { solvente (Tango, 1972) }\end{array}$ & $15,2-29,7$ & $2,8-11,7$ & $0,3-1,5$ & $36,9-71,6$ & $6,1-18,3$ \\
\hline Óleo bruto de abacate ${ }^{2}$ (Canto et al., 1980) & $16,0-25,0$ & $4,0-6,0$ & $0,1-1,5$ & $58,0-68,0$ & $7,0-13,0$ \\
\hline $\begin{array}{l}\text { Óleo de abacate de diferentes variedades (Tango e } \\
\text { Turatti, 1992) }\end{array}$ & $15,4-32,4$ & $2,8-9,1$ & $0,2-1,5$ & $44,0-69,6$ & $6,1-14,9$ \\
\hline Óleo de abacate, cultivar Wagner ${ }^{3}$ (Soares et al., 1991) & $20,5^{\mathrm{a}} ; 19,8^{\mathrm{b}} ; 20,2^{\mathrm{c}}$ & $\begin{array}{l}6,1^{\mathrm{a}} ; 5,9^{\mathrm{b}} \\
6,0^{\mathrm{c}} ; 6,2^{\mathrm{d}}\end{array}$ & - & $\begin{array}{l}61,5^{\mathrm{a}} ; 61,2^{\mathrm{b}} \\
59,8^{\mathrm{c}} ; 60,6^{\mathrm{d}}\end{array}$ & $\begin{array}{l}11,5^{\mathrm{a}} ; 11,9^{\mathrm{b}} ; \\
12,6^{\mathrm{c}} ; 12,9^{\mathrm{d}}\end{array}$ \\
\hline Óleo de oliva ${ }^{4}$ (Canto et al., 1980) & $11,0-19,0$ & $1,0-3,5$ & $1,5-3,5$ & $61,0-71,0$ & $11,0-17,0$ \\
\hline $\begin{array}{l}\text { Óleo de oliva refinado, enlatado na Europa }{ }^{5} \text { (Soares e } \\
\text { Amaya, 1981) }\end{array}$ & $10,0-12,2$ & $0,4-1,0$ & $2,4-2,7$ & $77,6-79,3$ & $5,5-9,5$ \\
\hline $\begin{array}{l}\text { Óleo de oliva refinado, enlatado na Argentina }{ }^{5} \text { (Soares e } \\
\text { Amaya, 1981) }\end{array}$ & $12,6-15,3$ & $1,0-1,2$ & $1,3-1,6$ & $70,1-74,6$ & $10,6-12,4$ \\
\hline Óleo de algodão ${ }^{4}$ (Canto et al., 1980) & - & $0,1-1,5$ & $1,5-3,1$ & $12,4-20,0$ & $48,6-58,7$ \\
\hline Óleo de amendoim ${ }^{4}$ (Canto et al., 1980) & $9,5-16,8$ & - & $2,9-5,5$ & $42,5-50,9$ & $26,2-43,6$ \\
\hline Óleo de gergelim ${ }^{4}$ (Canto et al., 1980) & $8,4-10,0$ & $0,1-2,0$ & $5,0-7,0$ & $31,0-48,0$ & $36,0-52,0$ \\
\hline Óleo de girassol ${ }^{4}$ (Canto et al., 1980) & $5,0-6,5$ & $0,1-0,3$ & $2,8-4,0$ & $18,0-36,0$ & $56,0-72,0$ \\
\hline Óleo de milho ${ }^{4}$ (Canto et al., 1980) & $9,6-14,5$ & - & $0,7-3,6$ & $32,4-46,3$ & $38,7-52,2$ \\
\hline Óleo de soja ${ }^{4}$ (Canto et al., 1980) & $9,3-12,5$ & - & $2,7-4,6$ & $19,9-25,0$ & $54,4-61,5$ \\
\hline
\end{tabular}

${ }^{1}$ Intervalo de variação dos resultados encontrados nesse artigo para as variedades avaliadas.

${ }^{2}$ Intervalo de variação das análises realizadas pelo ITAL de óleo bruto de diversas variedades de abacate.

${ }^{3}$ Valores médios de ácidos graxos de óleo extraído por centrifugação da polpa úmida e submetido ao processo de refino: ${ }^{\mathrm{a}}$ óleo bruto; ${ }^{\mathrm{b}}$ óleo neutro; ${ }^{\mathrm{c}}$ óleo clarificado; d óleo desodorizado.

${ }^{4}$ Composição de ácidos graxos segundo os padrões da Comissão Nacional de Normas e Padrões de Alimentos (CNNPA).

${ }^{5}$ Intervalo de variação da composição média de ácidos graxos de óleos de diferentes marcas, enlatados no país de origem.

colhidas no inverno e, possivelmente, foram influenciadas pelo estresse hídrico. Como há uma correlação linear negativa entre os teores de umidade e lipídeos, essas variedades provavelmente também sofreram influência quanto aos teores de lipídeos. Entretanto, ao expressar os teores de lipídeos em termos de matéria seca, ainda assim estas variedades, como as demais acima mencionadas, continuam a ser as principais produtoras de óleo.

A composição em ácidos graxos de óleo da polpa dos frutos de grande parte das variedades de abacate caracterizadas encontra-se na Tabela 4.

A variação da composição em ácidos graxos em função da variedade foi grande. As percentagens de ácido oléico variaram de 37,9 a $65,2 \%(C V=13,5 \%)$; de ácido palmítico de 14,5 a 35,2\% $(C V=20,6 \%)$; de ácido linoléico de 9,4 a 21,2\% (CV=19,8\%); de ácido palmitoléico de 2,9 a $16,8 \%(\mathrm{CV}=39,1 \%)$, e de ácido esteárico de quantidades traços a $0,7 \%(\mathrm{CV}=21,4 \%)$.

As cultivares Mayapan e Mac Donald demonstraram as menores concentrações de ácido oléico ( 37,9 e 40,8\%, respectivamente). Em contrapartida, Mac Donald obteve o maior teor de ácido palmítico $(35,2 \%)$; Mayapan, além de revelar uma alta concentração de ácido palmítico $(29,8 \%)$, obteve a maior porcentagem do ácido graxo palmitoléico (16,8\%). Quintal, Fuerte, Ouro Verde, Collinson, Linda e Pollock sobressaíram-se em relação às demais variedades por terem as mais elevadas concentrações dos ácidos graxos ômega nove (ao redor de $80 \%$ de ácido oléico, linoléico e palmitoléico).

Em comparação com outras fontes de óleos vegetais, demonstradas na Tabela 6, o óleo de abacate caracteriza-se por apresentar teores elevados de ácidos graxos monoinsaturados (oléico e palmitoléico), baixo teor de ácido graxo polinsaturado (linoléico), teor relativamente elevado do ácido graxo saturado palmítico e menor conteúdo do ácido esteárico (saturado). Sua composição em ácidos graxos é muito próxima ao óleo de oliva, principalmente quanto aos altos níveis de ácido oléico
(Turatti et al., 1985; Soares et al., 1991; Soares et al., 1992).

De acordo com a literatura, a composição de ácidos graxos do óleo de abacate varia de acordo com as cultivares, estágio de maturação, região anatômica do fruto e localização geográfica de crescimento da planta. No entanto e de modo geral, o principal ácido graxo predominante sempre é o ácido oléico, acompanhado pelos ácidos palmítico e linoléico (Tango et al., 1972; Ahmed e Barmore, 1990).

O óleo de abacate destinado para salada deve ser submetido ao processo de hibernalização para eliminação de uma das suas frações, a dos triglicerídeos saturados, que poderão turvar em baixas temperaturas.

Os caroços constituem uma grande porção dos frutos. Dessa forma, houve interesse em caracterizá-los, visando a futuros estudos sobre o aproveitamento desse volumoso subproduto. Tais estudos são essenciais para a redução do custo de produção do óleo comestível.

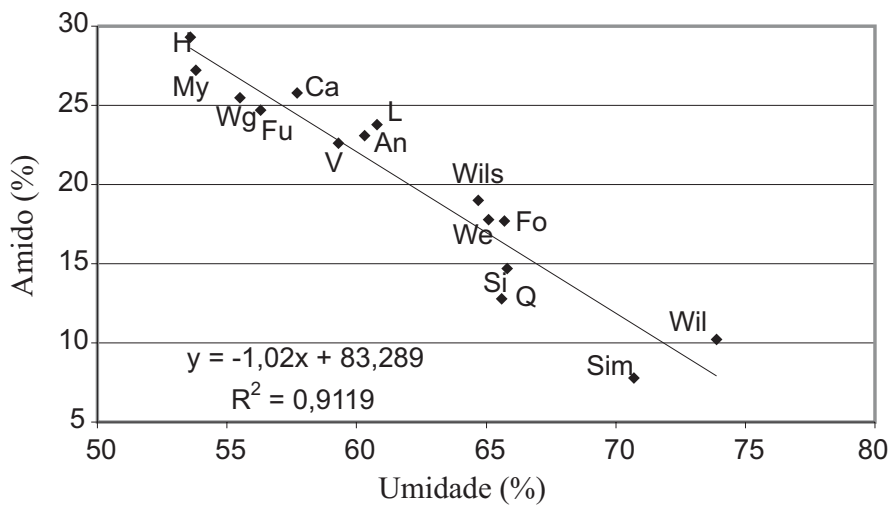

FIGURA 2 - Regressão linear dos teores de umidade e de amido encontrados nos caroços dos frutos de abacate. As variedades como os valores plotados correspondem à Tabela 6 . 
TABELA 7 - Composição química dos caroços de frutos de abacate de algumas das variedades analisadas, Campinas-SP, 1990.

\begin{tabular}{|c|c|c|c|c|c|c|c|c|}
\hline \multirow[b]{2}{*}{ VARIEDADES } & \multicolumn{8}{|c|}{ COMPOSIÇÃO QUÍMICA ${ }^{1}(\%)$} \\
\hline & Umidade & $\begin{array}{l}\text { Resíduo } \\
\text { Mineral }\end{array}$ & Lipídeos & $\begin{array}{c}\text { Proteína } \\
\text { Bruta }^{2}\end{array}$ & Fibra & Amido & $\begin{array}{c}\text { Substâncias } \\
\text { Fenólicas }\end{array}$ & Carboidratos $^{3}$ \\
\hline Anaheim (An) & 60,3 & 0,6 & 0,8 & 1,7 & 1,7 & 23,1 & 5,7 & 6,1 \\
\hline Carlsbad (Ca) & 57,7 & 0,6 & 1,0 & 1,6 & 1,6 & 25,8 & 2,7 & 9,0 \\
\hline Fortuna (Fo) & 65,7 & 1,8 & 0,7 & 2,1 & 3,1 & 17,7 & 3,8 & 5,1 \\
\hline Fuerte $(\mathrm{Fu})$ & 56,3 & 0,9 & 0,7 & 2,0 & 1,5 & 24,7 & 3,2 & 10,7 \\
\hline Hass $(\mathrm{H})$ & 53,6 & 0,9 & 0,8 & 1,6 & 1,6 & 29,3 & 3,1 & 9,1 \\
\hline Linda (L) & 60,8 & 0,4 & 0,9 & 2,1 & 1,7 & 23,8 & 2,8 & 7,5 \\
\hline Mayapan (My) & 53,8 & 1,1 & 0,9 & 3,0 & 2,3 & 27,2 & 3,6 & 8,1 \\
\hline Quintal (Q) & 65,6 & 1,1 & 1,0 & 2,3 & 1,8 & 12,8 & 3,8 & 11,6 \\
\hline Simmonds (Sim) & 70,7 & 0,4 & 0,9 & 1,7 & 0,8 & 7,8 & 4,5 & 13,2 \\
\hline Sinaloa $(\mathrm{Si})$ & 65,8 & 0,5 & 1,1 & 1,9 & 1,3 & 14,7 & 3,3 & 11,4 \\
\hline Vitória (V) & 59,3 & 0,7 & 0,5 & 2,2 & 1,2 & 22,6 & 2,3 & 11,2 \\
\hline Wagner (Wg) & 55,5 & 1,0 & 0,8 & 2,0 & 2,4 & 25,5 & 3,7 & 9,1 \\
\hline Westin (We) & 65,1 & 0,5 & 0,6 & 1,9 & 1,4 & 17,8 & 3,3 & 9,4 \\
\hline Winslow (Wil) & 73,9 & 0,7 & 0,3 & 1,4 & 1,4 & 10,2 & 2,6 & 9,5 \\
\hline Winslowson (Wils) & 64,7 & 0,5 & 0,5 & 2,0 & 1,3 & 19,0 & 2,7 & 9,3 \\
\hline MÉDIA & 61,9 & $\mathbf{0 , 8}$ & 0,8 & 2,0 & 1,7 & 20,1 & 3,4 & 9,3 \\
\hline CV $(\%)^{4}$ & 9,8 & 46,3 & 27,4 & 19,0 & 33,1 & 32,3 & 25,2 & 22,8 \\
\hline
\end{tabular}

${ }^{1}$ Médias de três determinações analíticas.

${ }^{2}(\% \mathrm{~N}$ x 6,25$)$

${ }^{3}$ Nesses valores não estão incluídos os teores de amido e fibra; calculados usando a fórmula: ( $100 \%$ - soma dos demais componentes químicos).

${ }^{4}$ Menor ou maior coeficiente de variação indica menor ou maior variabilidade do componente analisado em relação ao germoplasma.

As composições químicas dos caroços dos frutos de algumas das variedades podem ser vistas na Tabela 7.

Os caroços apresentaram teores de umidade variando de 53,6 a $73,9 \%(\mathrm{CV}=9,8 \%)$, tendo como média geral $61,9 \%$. As variedades em que os caroços foram caracterizados e que apresentaram teores de lipídeos nas polpas acima de $18 \%$ (Anaheim, Carlsbad, Fuerte, Hass, Mayapan e Wagner), revelaram suas percentagens de umidade nos caroços abaixo da média (61,9\%). Essas variedades apresentaram, também, conteúdos de umidade mais baixos nas polpas do que a média geral correspondente.

As percentagens de lipídeos, proteína bruta, resíduo mineral e fibra encontradas nos caroços foram muito baixos, correspondendo em média a 5,3\% da composição química. Os teores de amido variaram entre 7,8 e 29,3\% (CV=32,3\%), tendo 20,1\% como média geral. As sementes dos frutos das cultivares ricas em óleo nas polpas apresentaram teores de amido acima da média geral. Houve alta correlação linear negativa entre os teores de amido e de umidade encontrados nos caroços dos frutos, com alto coeficiente de correlação igual a - 0,955 (Tabela 3; Figura 2).

A principal dificuldade na utilização dos caroços de abacate é a presença de substâncias fenólicas, que apresentam toxidez para animais monogástricos. Ichimaru et al.(1982) demonstraram que, pela extração dessas substâncias com etanol, os caroços poderiam ser usados na alimentação dos animais monogástricos. $\mathrm{O}$ extrato fenólico poderá ter atividade antioxidante (Arellano, 1985). As percentagens dessas substâncias antinutricionais nos caroços variaram entre 2,3 e 5,7\% (CV $=25,2 \%$ ), tendo como média geral 3,4\% (Tabela 7).

Além do amido e fibra, existem outras substâncias não nitrogenadas presentes nos caroços, variando entre 5,1 e 13,2\% e com alta dispersão dos resultados ( $\mathrm{CV}=22,8 \%$; Tabela 7).

Diante do exposto, há a possibilidade de estabelecer-se plantações de abacateiros, com variedades que apresentem altos teores de óleo na polpa dos frutos e diferentes épocas de maturação, o que poderá levar à instalação de indústrias de extração e refino de óleo de abacate para fins comestíveis, contribuindo para a expansão industrial e da fruticultura, além de proporcionar economia de divisas na importação de óleo de oliva e oferecer melhoria à saúde dos consumidores.

\section{CONCLUSÕES}

1) As variedades de abacate Anaheim, Carlsbad, Collinson,
Fuerte, Glória, Hass, Itzamna, Mayapan, Ouro Verde e Wagner, apesar de algumas apresentarem alta proporção de cascas e sementes, são alternativas para extração de óleo devido ao alto teor de lipídeos de suas polpas.

2) Para as vinte e quatro variedades de abacate avaliadas, houve correspondência funcional altamente significativa entre as proporções de polpa com as de caroço e casca dos frutos.

3) Dentre as variedades estudadas, a Quintal apresentou as menores porcentagens de casca e semente e a maior proporção de polpa dos frutos.

4) Houve alta correlação linear negativa entre os teores de umidade e lipídeos presentes nas polpas e entre os teores de amido e umidade nas sementes dos frutos.

5) Ocorreu grande variação da composição de ácidos graxos constituintes do óleo das polpas. As variedades Quintal, Fuerte, Ouro Verde, Collinson, Linda e Pollock, com maiores teores de ácidos graxos insaturados (oléico, linoléico e palmitoléico), são as mais indicadas para o consumo humano com relação ao controle de colesterol.

\section{REFERÊNCIASBIBLIOGRÁFICAS}

AHMED, E. M.; BARMORE, C. R. Avocado. In: NAGY, S.; SHAW, P.E.; WARDOWSKI, W.F. (Ed.) Fruits of tropical and subtropical origin: composition, properties and uses. Lake Alfred: AVI Publishing, 1990. p. 121-156.

ARELLANO, D. B. Atividade antioxidante de extratos liofilizados de plantas brasileiras. 1985. 154f. Tese (Doutorado) - Faculdade de Engenharia de Alimentos e Agrícola, Universidade Estadual de Campinas, Campinas, 1985.

BEYTHIEN, A.; DIEMAIR, W. Laboratoriumsbuch für der lebensmittelchemiker. Leipzig: Verlag von Theodor Steinkopff, 1963. p. 28-29.

BIZIMANA, V.; BREENE, W.M.; CSALLANY,A.S. Avocado oil extraction with appropriate technology for developing countries. Journal of the American Oil Chemists' Society, Champaign, v. 70, n. 8, p. 821$822,1993$.

BLEINROTH, E. W.; CASTRO, J. V. de. Matéria-prima. In: ABACATEcultura, matéria-prima, processamento e aspectos econômicos. Campinas: ITAL, 1992.p. 58-147. 
CANTO, W. L.; SANTOS, L. C.; TRAVAGLINI, M. M. E. Óleo de abacate: extração, usos e seus mercados atuais no Brasil e na Europa. Estudos Econômicos. Campinas: ITAL, 1980. 144p. (Alimentos Processados, 11)

FISCHER, R.A. Statistical methods for research workers. 9. ed. London: Oliver and Boyd, 1994. p.194.

ICHIMARU, D. L.; SALES, A. M.; IADEROZA, M.; BALDINI, V. L. S. Estudo dos fatores antinutricionais do caroço de abacate (Persea americana Mill. cv. Wagner). Coletânea do ITAL, Campinas, v. 12, p. $67-83,1982$.

JAUBERT, J. N. Une nouvelle technique de préparation et de raffinage de 1'huile d'avocat. Fruits, Paris, v. 25, n. 4, p. 292-294, 1970.

JIMENEZ, O. El aceite de aguacate. Suelo Tico, San Jose, v. 7, n. 30, p. 221-226, 1954.

MONTANO, G. H.; LUH, B. S.; SMITH, L. M. Extracting and refining avocado oil. Food Technology, Chicago, v. 16, n. 2, p. 96-101, 1962.

OLAETA, J.A.C; UNDURRAGA, P.M. Estimacion del indice de madurez en paltos. In: KUSHWAHA, L.; SERWATOWSKI, R.; BROOK, R. (Ed.) Harvest and postharvest technologies for fresh fruits and vegetables: proceedings of the international conference. Guanajuato: ASAE, 1995, p. 421-426.

REBOLLO, A. J.G.; BOTEJA, E, M.; CANSADO, A. O.; BLANCO, P.J.M.; BELLIDO, M.M.; SÁNCHEZ, A.F.; ARIAS, P.M; ALVAREZ, J.E.C. Effects of comsumption of meat product rich in monounsaturated fatty acids (the ham from the Iberian pig) on plasma lipids. Nutrition Research, Tarrytown, v.18, p. 743-750, 1998.

SADIR, R. Olio di abacate: tecnologia dell'estrazione e industrializzazione dei residui. La Rivista Italiana delle Sostanze Grasse, Milan, v. 49, n. 2, p. 90-93, 1972a.

SADIR, R. Olio di abacate: tecnologia della raffinazione. La Rivista Italiana delle Sostanze Grasse, Milan, v. 49, n. 3, p. 117-120, 1972 b.

SANTOS, L. C. Estudo sobre refinação do óleo de abacate de variedade (Persea americana Mill.) Wagner. 1985. 65f. Tese (Mestrado) Escola Superior de Agricultura "Luiz de Queiroz", Universidade de São Paulo, Piracicaba, 1985.

SOARES, S.E.; MANCINI FILHO, J.; TURATTI, J.M.; TANGO, J.S.
Caracterização física, química e avaliação da estabilidade do óleo de abacate (Persea americana, Mill.) nas diferentes etapas do processo de refinação. Revista de Farmácia e Bioquímica da Universidade de São Paulo. São Paulo, v. 27, n.1, p. 70-82, 1991.

SOARES, S.E.; MANCINI FILHO, J.; DELLAMODESTA, R.C. Sensory detection limits of avocado oil in mixtures with olive oil. Revista Española de Ciencia y Tecnologia de Alimentos, v. 32, n. 5, p. 509516, 1992.

SCHORMULLER, J. Handbuch der lebensmittelchemie. Band II/Teil 2: analitik der lebensmittel. Nachweis und bestimmung von lebensmittel-inhaltstoffe. Berlin: Spring-Verlag, 1967. p. 444-445.

SENTELHAS, P.C.; PIZA JÚNIOR, C.T.; ALFONSI, R. R.; KAUATI,R.; SOARES, N. B. Zoneamento climático da época de maturação do abacateiro no Estado de São Paulo. Revista Brasileira de Agrometeorologia, Santa Maria, v. 3, p.133-140, 1995.

SMITH, L.M.; WINTER, F.H. Research on avocado processing at the University of California. California Avocado Society, Saticoy, v. 54, p. 79-83, 1970/71. (1970/71 Yearbook).

TANGO, J. S.; COSTA, S. I.; ANTUNES, A. J.; FIGUEIREDO, I. B. Composition du fruit et de l'huile de différentes variétés d'avocats cultivés dans l'Etat de São Paulo, Fruits, Paris, v. 27, p. 143-146, 1972.

TANGO, J. S.; TURATTI, J. M. Óleo de abacate. In: ABACATE - cultura, matéria-prima, processamento e aspectos econômicos. Campinas: ITAL, 1992. p. 156-192.

TURATTI, J. M.; GOMES, R.A.R.; ATHIÉ, I. Lipídeos: aspectos funcionais e novas tendências. Campinas: ITAL, 2002, 78p.

TURATTI, J. M.; SANTOS, L. C. dos; TANGO, J. S.; ARIMA, H. K. Caracterização do óleo de abacate obtido por diferentes processos de extração. Boletim do ITAL, Campinas, v. 22, p. 267-284, 1985.

WALKER, R.O. (Ed.) Official and tentative methods of the american oil chemists' society: including additions and revisions. 3. ed. Champaign: AOCS, 1979.v. 1.

WILLIAMS, S. (Ed.). Official methods of analysis. 14th ed. Arlington: Association of Official Analytical Chemists, 1984. 1141p. 